\title{
Avaliação de algumas propriedades funcionais das farinhas de tremoço doce (Lupinus albus) e feijão guandu (Cajanus cajan (L) Millsp) e sua utilização na produção de fiambre
}

\author{
Evaluation of some functional properties of lupin sweet flour (Lupinus albus) and faba bean flour \\ (Cajanus cajan (L) Millsp) and their utilization in cooked ham production
}

Fernando CASTILHO ${ }^{1}$, Gustavo Guadagnucci FONTANARI ${ }^{1 *}$, José Paschoal BATISTUTI ${ }^{1 *}$

\begin{abstract}
Resumo
$\mathrm{O}$ aumento na demanda de alimentos no mundo tem motivado pesquisadores a buscarem fontes alternativas a fim de enriquecer nutricionalmente alimentos industrializados e torná-los viáveis economicamente às populações menos favorecidas. O tremoço doce e o feijão guandu são leguminosas com elevado conteúdo proteico e grande potencial de utilização no enriquecimento nutricional de alimentos industrializados, além de desempenharem funcionalidades. Os resultados obtidos neste trabalho permitiram observar que a farinha de tremoço doce é capaz de absorver de 172 a 186\% do seu peso em água e de $62 \%$ em óleo, enquanto que a farinha de feijão guandu absorve cerca de $100 \%$ de seu peso em água e $50 \%$ em óleo. Boa atividade e estabilidade foram observadas para as emulsões obtidas com estas farinhas, indicando potencial de aplicação na produção de embutidos. Objetivou-se neste trabalho, avaliar algumas propriedades funcionais das farinhas de tremoço doce e feijão guandu e sua utilização na fabricação de fiambres. Os fiambres foram elaborados no Laboratório de Controle de Qualidade de Alimentos da Faculdade de Ciências Farmacêuticas da Universidade Estadual Paulista (UNESP), na cidade de Araraquara, com o intuito de oferecer um alimento enriquecido nutricionalmente. Quando comparados ao fiambre elaborado com a adição de concentrado proteico de soja, estes fiambres não apresentaram diferenças significativas nos atributos sensoriais aparência, cor, aroma, textura e impressão global, embora tivessem pouca aceitabilidade sensorial.

Palavras-chave: propriedades funcionais; tremoço doce; feijão guandu; fiambre.
\end{abstract}

\begin{abstract}
The increase in food demand worldwide has motivated researchers to seek alternative food crops to nutritionally enrich industrialized foods and make them economically viable to poorer populations. Sweet lupin and faba bean are high protein content legumes of great potential for nutritional enrichment of industrialized foods, besides performing a functional purpose. The results obtained in this work enabled to identify that sweet lupin flour is able to absorb 172 to $186 \%$ of its weight in water, and $\sim 62 \%$ in oil, while faba bean flour absorbs $~ 100 \%$ of its weight in water, and $\sim 50 \%$ in oil. The emulsions obtained with both flours showed good activity and stability, suggesting a good application potential in the production of sausages. In the present work, some functional properties of the sweet lupin and faba bean flours were analyzed, including use in the production of cooked ham. The cooked ham was elaborated in the Quality Control Laboratory of foods in the Pharmaceutical Sciences Faculty in the University of São Paulo State (UNESP) in Araraquara (SP, Brazil), offering an enriched food nutritionally. When compared to cooked hams prepared with the addition of soy protein, the experimental hams presented no significant sensorial differences, such as appearance, color, flavor, texture and overall impression, however they had had little sensorial acceptability.

Keywords: functional properties; sweet lupin; faba bean; cooked ham.
\end{abstract}

\section{Introdução}

Circunstâncias socioeconômicas aliadas à globalização têm estimulado a procura por fontes alternativas para a alimentação bem como por novos processos tecnológicos, visando a redução dos custos dos produtos e de impacto positivo no atendimento das demandas nutricionais, inclusive às das classes menos favorecidas (BATISTUTI; FREITAS, 1995). As proteínas de origem vegetal, em particular as proteínas de leguminosas, representam alternativas com grande potencial de uso na formulação de alimentos como ingredientes proteicos (ADAWY et al., 2001; DRAKOS; DOXASTAKIS; KIOSSEOGLOU, 2007; LAWAL, 2004).
Alguns estudos estão sendo realizados no intuito de procurar fontes alternativas de produtos proteicos a fim de desempenhar funcionalidade, como, por exemplo, formar emulsão e agregar valor nutricional em alimentos industrializados (FONTANARI et al., 2006, 2007, 2008), assim como o aproveitamento de resíduos remanescentes gerados pelo processamento industrial de alimentos (EL AAL, 1992; FONTANARI et al., 2006; LIADAKIS et al., 1995; NICANOR et al., 2005).

A emulsão é uma funcionalidade que compreende a dispersão de dois líquidos imiscíveis, tendo uma fase dispersante

Recebido para publicação em 15/3/2008

Aceito para publicação em 5/1/2009 (003174)

'Departamento de Alimentos e Nutrição, Faculdade de Ciências Farmacêuticas - UNESP, CEP 14801-902, Araraquara - SP, Brasil, E-mails: guganari@fcfar.unesp.br; batistut@fcfar.unesp.br

${ }^{*}$ A quem a correspondência deve ser enviada 
como fase contínua e uma fase dispersa na forma de gotículas. Em geral, as emulsões alimentares são do tipo óleo em água $(\mathrm{O} / \mathrm{A})$ ou água em óleo (A/O), em que o termo óleo designa um líquido hidrófobo (ORNELLAS; JUNQUEIRA; SILVESTRE, 2000).

As proteínas de origem vegetal, em particular a da soja, são incorporadas nos produtos embutidos à base de carne no intuito de melhorar suas propriedades de emulsão e de textura, principalmente após a cocção (BARBUT, 1994; RHEE, 1994). De acordo com Pozani, Doxastakis e Kiosseoglou (2002) as proteínas de tremoço possuem importantes propriedades de emulsão e contribuem para a estabilização das partículas de gordura, contidas em emulsão, em sistemas que contenham carnes. Drakos, Doxastakis e Kiosseoglou (2007) utilizaram a proteína do tremoço na formação de emulsão e aplicação em produtos cárneos, revelando boas propriedades de textura, obtendo um produto estável de boa aceitabilidade sensorial.

Do mesmo modo, Cepeda, Villarán e Aranguiz (1998) relataram para o feijão guandu boas propriedades de retenção de água e óleo, bem como a estabilidade das emulsões formadas. Entretanto poucos relatos são observados para o uso dessas fontes na produção de fiambres, principalmente para a proteína do feijão guandu.

Entende-se por Fiambre o produto cárneo industrializado, obtido de carne de uma ou mais espécies de animais de açougue, miúdos comestíveis, adicionado de ingredientes e submetido a processo térmico adequado (BRASIL, 2000).

Nesse propósito, o objetivo deste trabalho foi a avaliação de algumas propriedades funcionais emulsificantes das farinhas de tremoço doce e de feijão guandu e suas utilizações na obtenção de fiambre, e a avaliação de sua aceitabilidade.

\section{Material e métodos}

\subsection{Material}

O material utilizado nos experimentos é composto pelas farinhas de tremoço doce, farinha de feijão guandu, concentrado proteico de soja e as respectivas formulações de fiambre.

\subsection{Produção das farinhas}

As sementes de tremoço doce (Lupinus albus), cultivar Multolupa, foram obtidas junto à fazenda experimental da Empresa Brasileira de Pesquisas Agropecuárias (EMBRAPA) Passo Fundo - RS; as sementes de feijão guandu (Cajanus cajan (L.) Millsp) variedade fava larga (safra 2001), foram obtidas junto ao Instituto Agronômico de Campinas (IAC), da fazenda experimental de Pindorama - SP. Ambas foram descorticadas, secas, trituradas em moinho de bolas e classificadas em tamis de abertura de 0,250 $\mathrm{mm}$ (60 mesh). O concentrado proteico de soja (Glycine max) foi adquirido em estabelecimento comercial local, assim como a proteína e a gordura animal (pernil suíno inteiro desossado) utilizadas na produção dos fiambres.

\subsection{Produção dos fiambres}

Para a formulação dos fiambres utilizou-se o método básico desenvolvido por Roça, Serrano e Bonassi (1988). Realizaramse três tratamentos contendo $10 \%$ de ingrediente de origem vegetal (farinha de tremoço doce, farinha de feijão guandu e concentrado proteico de soja), sendo que os ingredientes foram hidratados com água na proporção de 1:2, respectivamente. Os demais ingredientes (90\%) foram: proteína e gordura de origem animal (pernil suíno) calculadas para $800 \mathrm{~g}$ de massa, conforme apresentado na Tabela 1 .

À massa homogeneizada foi então acrescentada a mistura de cura com os condimentos e foi mantida durante duas horas na temperatura ambiente a fim de realizar o processo de cura; após essa etapa foi acondicionada em formas metálicas e submetida ao tratamento térmico (aquecimento em banho-maria sob temperatura de $85{ }^{\circ} \mathrm{C}$ por 80 minutos). Posteriormente foi resfriada em água corrente, pesada, acondicionada em embalagens plásticas de polietileno e o produto foi armazenado sob refrigeração $\left(5-10^{\circ} \mathrm{C}\right)$ para análises posteriores.

Tabela 1. Ingredientes utilizados nas formulações dos fiambres com: concentrado proteico de soja (CPS), farinha de tremoço doce (FTD) e farinha de feijão guandu (FFG).

\begin{tabular}{|c|c|c|c|}
\hline \multirow[t]{2}{*}{ Ingredientes } & \multicolumn{3}{|c|}{ Valores expressos em gramas } \\
\hline & CPS & FTD & FFG \\
\hline Sal & 16,0 & 16,0 & 16,0 \\
\hline Açúcar & 4,0 & 4,0 & 4,0 \\
\hline Antioxidante (ac. Ascórbico) & 2,0 & 2,0 & 2,0 \\
\hline Estabilizante comercial (polifosfato) & 4,0 & 4,0 & 4,0 \\
\hline Nitrito de Sódio $\left(\mathrm{NaNO}_{2}\right)$ & 0,16 & 0,16 & 0,16 \\
\hline Farinha de tremoço doce & 0 & 80,0 & 0 \\
\hline Farinha de feijão guandu & 0 & 0 & 80,0 \\
\hline Mistura de proteína e gordura suína & $\cong 690,0$ & $\cong 690,0$ & $\cong 690,0$ \\
\hline
\end{tabular}

Fonte: (ROÇA; SERRANO; BONASSI, 1988). 


\subsection{Determinação da composição química das farinhas de tremoço doce e feijão guandu, pernil suíno moído e dos fiambres crus e cozido}

O teor de umidade, gordura e cinzas das farinhas de tremoço doce e feijão guandu foram determinados de acordo com os métodos descritos pela AOAC (Association of Official Analytical Chemists, 1995). Para a determinação de nitrogênio, foi utilizado o método de KJELDAHL e o fator de 6,25 para a determinação da proteína. Os carboidratos totais foram determinados por diferença entre 100 e o somatório das frações proteicas, lipídicas, de umidade e de cinzas. A composição química do concentrado proteico de soja foi fornecida pelo fabricante.

\subsection{Determinação de amido e açúcares redutores}

A determinação de amido foi realizada segundo procedimento descrito pela AOAC (ASSOCIATION OF OFFICIAL ANALYTICAL CHEMISTS, 1995) e os açúcares redutores foram determinados pelo procedimento descrito pela ABNT (ASSOCIAÇÃO BRASILEIRA DE NORMAS TÉCNICAS, 1997).

\subsection{Determinação do valor calórico do pernil suíno moído e dos fiambres, antes e após a cocção, e das farinhas de tremoço doce e feijão guandu}

A determinação do valor calórico do pernil suíno e dos fiambres crus e cozidos foi realizada com o auxílio de um Calorímetro PARR 1281; já para o cálculo do valor calórico das farinhas, utilizaram-se os coeficientes de Atwater (WATT;

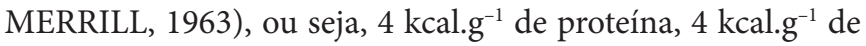
carboidratos e 9 kcal.g ${ }^{-1}$ de gorduras.

\subsection{Determinação do pH do pernil suíno moído e dos fiambres cru e cozido}

A determinação do $\mathrm{pH}$ foi realizada segundo as normas analíticas do IAL (Instituto Adolfo Lutz, 1976), utilizando-se um potenciômetro digital Sentron com eletrodo de penetração.

\subsection{Capacidades de absorção de água (CAA) e óleo (CAO) das farinhas de tremoço doce e feijão guandu}

As CAA e CAO foram determinadas usando-se o método de Wang e Kinsella (1976) com modificações. Dois gramas (2g) de farinha foram homogeneizados com $10 \mathrm{~mL}$ de água destilada e/ou óleo de soja por 2 minutos; as amostras permaneceram em repouso à temperatura ambiente $(25 \pm 3){ }^{\circ} \mathrm{C}$, por 15 minutos; e a seguir foram centrifugadas a $8.000 \mathrm{rpm} / 10$ minutos. $\mathrm{O}$ volume do sobrenadante foi coletado em proveta graduada de capacidade para $10 \mathrm{~mL}$. A capacidade de absorção foi determinada pela diferença entre o volume inicial e o volume final; e os resultados foram expressos em $\mathrm{mL}$ de água e/ou óleo absorvido por grama de farinha (mL.g farinha).

\subsection{Determinação da capacidade de emulsificação das farinhas de tremoço doce e feijão guandu}

A capacidade de emulsificação foi determinada pelo método de Wang e Kinsella (1976). Alíquotas de farinhas contendo pesos diferentes foram pesadas em béquer de $50 \mathrm{~mL}$ e homogeneizadas em $20 \mathrm{~mL}$ de água destilada. A mistura foi mantida sob agitação magnética por 10 minutos, sendo, em seguida, transferida para copo de alumínio adaptado para liquidificador usado para este procedimento. $\mathrm{O}$ béquer foi lavado com $5 \mathrm{~mL}$ de água para a retirada de possíveis resíduos. Em seguida a mistura foi homogeneizada (velocidade $16.000 \mathrm{rpm}$ ) e a adição de óleo de soja, em fluxo constante (69 mL/minuto), ocorreu até o momento de quebra da emulsão, determinada pela mudança de viscosidade da mistura. A quantidade de óleo emulsionado foi determinada pela diferença de peso do seu reservatório. Os resultados foram expressos em gramas de óleo emulsionado por grama de proteína.

\subsection{Determinação da estabilidade da emulsão (EE) e da atividade emulsificante (AE) das farinhas de tremoço doce e feijão guandu}

A EE foi determinada pelo método de Action e Saffle (1970) com algumas modificações. Suspensões contendo $22 \mathrm{~mL}$ de água destilada com alíquotas de farinhas equivalentes a 1,12 g de proteína de cada leguminosa foram homogeneizadas em agitador magnético por 10 minutos; em seguida foram transferidas para copo de alumínio adaptado para liquidificador, na velocidade de $16.000 \mathrm{rpm}$, com $15 \mathrm{~mL}$ de óleo de soja, até completa homogeneização. A emulsão formada foi dividida em tubos com tampa e mantidas por 30 minutos em béquer contendo gelo. Posteriormente foi centrifugada a $3000 \mathrm{rpm} / 30$ minutos; descartou-se a água liberada e pesaram-se os tubos. A EE foi determinada através da diferença do peso entre a emulsão formada antes da centrifugação e após a centrifugação. A EE foi expressa em $\mathrm{mL}$ de água liberada.

A AE foi determinada pelo mesmo método citado acima, porém os tubos foram mantidos em banho de água a $80^{\circ} \mathrm{C}$. A AE foi determinada através da diferença do peso entre a emulsão formada antes da centrifugação e após a centrifugação. A AE foi expressa em $\mathrm{mL}$ de água liberada.

\subsection{Determinação das perdas de peso por cocção dos fiambres}

A determinação das perdas de peso por cocção foi realizada através da variação de peso das amostras antes e após serem submetidas ao cozimento em banho-maria à temperatura de $85^{\circ} \mathrm{C}$ por 80 minutos. Finalmente calculou-se a porcentagem de perda pela diferença de peso entre os fiambres crus e os cozidos.

\subsection{Avaliação da textura dos fiambres}

Para a avaliação da textura dos fiambres foi determinada a força necessária para o cisalhamento completo das amostras, previamente cortadas em pequenos cubos de aproximadamente $5 \times 5 \times 5 \mathrm{~cm}$, em aparelho Analisador de Textura acoplado ao dispositivo Warner-Bratzler, para a medida da força de cisalhamento da amostra (expresso em $\mathrm{kgf.cm}{ }^{-2}$ ).

\subsection{Avaliação da cor dos fiambres}

Para a avaliação da cor dos produtos, as peças foram cortadas ao meio, e foi medida a cor em colorímetro Minolta 
CR-200, o qual considera no seu sistema as coordenadas $\mathrm{L}^{\star}, \mathrm{a}^{*}$ $\mathrm{e}^{\star}$, responsáveis pela luminosidade, teor de vermelho e teor de amarelo, respectivamente. $\mathrm{O}$ aparelho foi previamente calibrado em superfície branca de acordo com padrões pré-estabelecidos, com média de 3 pedaços de fiambre por repetição (BIBBLE; SINGHA, 1993).

\subsection{Avaliação sensorial dos fiambres}

A avaliação sensorial foi realizada no Laboratório de Análise Sensorial de Alimentos do Departamento de Alimentos e Nutrição da Faculdade de Ciências Farmacêuticas da Universidade Estadual Paulista (FCFAR/UNESP). Foram empregados teste de aceitação com escala hedônica não estruturada de nove pontos ( $9=$ gostei muitíssimo a $1=$ desgostei muitíssimo). As seguintes variáveis foram analisadas por 50 provadores não treinados na faixa etária de 18 a 30 anos, escolhidos aleatoriamente: aparência; coloração; aroma; sabor; textura; e impressão global. Foi, também, solicitado ao provador para indicar qualquer particularidade observada e que merecesse destaque. As amostras foram apresentadas de forma monádica acompanhadas de copo de água, e as avaliações foram realizadas em cabines individuais.

\subsection{Análise estatística}

Os resultados experimentais foram comparados por ANOVA e teste de Tukey para determinação da diferença estatística entre as médias ( $\mathrm{p}<0,05)$, utilizando-se o programa BioEstat 4.0 para windows (AYRES et al., 2005).

\section{Resultados e discussão}

\subsection{Composição química das farinhas de tremoço doce e feijão guandu e do pernil suíno moído desossado}

A Tabela 2 apresenta os valores da composição química das amostras investigadas. Para a farinha de tremoço doce, observase maior quantidade de proteína em relação à farinha de feijão guandu, apresentando um valor de aproximadamente $41 \%$; valores inferiores foram relatados por Martínez-Villaluenga,
Frías e Valverde (2006) (30,6\% \pm 0,26) e Lqari et al. (2002) $(33,8 \% \pm 6,9)$.

Para a farinha de feijão guandu, os valores de proteínas estão em concordância com os encontrados na literatura, que apontam conteúdo proteico de $15,5 \%$ a $28,8 \%$ (SALUNKHE; CHAVAN; KADAM, 1986) e 22,4\% (OSHODI; EKPERIGIN, 1989). Entretanto, esses valores são inferiores quando comparados a outras leguminosas: soja integral (44,03\%); farelo de amendoim (51,78\%); feijão branco cozido Phaseolus vulgaris (28,47\%); feijão

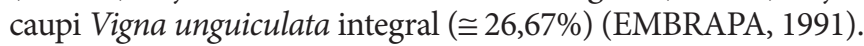

Valores reduzidos de açúcares redutores foram observados para a farinha de tremoço doce $\left(94,20 \mathrm{mg} .100 \mathrm{~g}^{-1}\right)$ em relação à farinha de feijão guandu $\left(129,15 \mathrm{mg} \cdot 100 \mathrm{~g}^{-1}\right)$. Além de potencializar o sabor dos alimentos, os açúcares redutores auxiliam no desenvolvimento da cor em alimentos cozidos, devido à reação de Maillard que ocorre durante o processo de cocção. Em alguns casos, este tipo de reação torna-se útil no desenvolvimento de cor e sabor desejáveis (BOBBIO, P. A.; BOBBIO, F. O., 2001).

\subsection{Capacidade de absorção de água (CAA) e óleo (CAO)}

A capacidade de absorção de água e óleo das farinhas de tremoço doce e de feijão guandu foi avaliada e seus resultados estão expressos na Tabela 3. De acordo com a tabela, nota-se que as farinhas tiveram maior afinidade pela água que pelo óleo.

As propriedades funcionais de interação de proteína-água (retenção de água) são importantes na formulação de determinados alimentos, sobretudo derivados de carne (embutidos, salsichas, almôndegas e salgados), nos quais as proteínas também exercem papel de espessamento, conferindo mais consistência ao produto (CHEFTEL; CUQ; LORIENT, 1985).

Cheftel, Cuq e Lorient (1985) sugeriram que a absorção e retenção de água pelas proteínas exercem importante papel na qualidade da textura de diversos alimentos, notadamente produtos derivados da carne. Da mesma maneira a capacidade de absorção de óleo também é requerida nas formulações de carne, substitutos de carne e análogos (ABBEY; IBEH, 1988). De acordo com os resultados apresentados na Tabela 3, ambas as

Tabela 2. Composição química da farinha de tremoço doce (Lupinus albus) cv. Multolupa, farinha de feijão guandu (Cajanus cajan (L) Millsp), concentrado proteico de soja e pernil desossado.

\begin{tabular}{|c|c|c|c|c|}
\hline Componentes & Farinha de tremoço Doce* & Farinha de feijão guandu* & Concentrado proteico de soja & Pernil desossado $^{*}$ \\
\hline Calorias $\left(\right.$ Kcal.100 g $\left.\mathrm{g}^{-1}\right)$ & $356,65 \pm 0,5^{\star *}$ & $274,8 \pm 0,6^{\star *}$ & 340,0 & $164,06 \pm 0,5$ \\
\hline Carboidrato (g.100 g $\left.\mathrm{g}^{-1}\right)$ & $28,74 \pm 0,5^{\dagger}$ & $42,36 \pm 0,5^{\dagger}$ & 30,0 & - \\
\hline Umidade (g.100 g $\left.\mathrm{g}^{-1}\right)$ & $6,50 \pm 0,5$ & $8,07 \pm 0,4$ & - & $69,58 \pm 0,6$ \\
\hline Cinzas (g.100 g $\left.{ }^{-1}\right)$ & $3,71 \pm 0,4$ & $3,04 \pm 0,5$ & - & $1,39 \pm 0,6$ \\
\hline Gordura (g.100 g g $^{-1}$ ) & $8,57 \pm 0,6$ & $2,00 \pm 0,5$ & 0 & $5,61 \pm 0,5$ \\
\hline Proteína (g.100 g g $\left.^{-1}\right)$ & $41,14 \pm 0,5$ & $21,84 \pm 0,6$ & 54,0 & $22,08 \pm 0,7$ \\
\hline Fibras (g.100 g-1) & $11,34 \pm 0,7$ & $7,41 \pm 0,7$ & 16,0 & - \\
\hline Amido (g.100 g $\left.{ }^{-1}\right)$ & - & $57,33 \pm 0,7$ & - & - \\
\hline Açúcares redutores (mg.100 g $\left.{ }^{-1}\right)$ & $94,20 \pm 0,8$ & $129,15 \pm 0,8$ & - & - \\
\hline $\mathrm{pH}$ & _- & _- & _- & $5,36 \pm 0,4$ \\
\hline
\end{tabular}

${ }^{\star}$ Médias \pm desvio padrão de três determinações calculadas em base úmida; ${ }^{* *}$ Valores obtidos através do fator de Atwater; †valores obtidos por diferença. 
farinhas apresentaram valores satisfatórios para desempenharem funcionalidade em alimentos industrializados (LQARI et al., 2002; SILVA; BORA; QUEIROGA NETO, 1997).

\subsection{Determinação da capacidade de emulsificação das farinhas de tremoço doce e feijão guandu}

Na Tabela 3 estão apresentados os resultados da capacidade de emulsificação para a farinha de tremoço doce e feijão guandu.

De acordo com os resultados expressos na Tabela 3, a farinha de feijão guandu apresentou maior capacidade de emulsão que a farinha de tremoço doce.

Por outro lado, os resultados também demonstraram melhor desempenho de ambas as farinhas quando comparadas a outras sementes de leguminosas como, por exemplo: great northen bean (39,6 g óleo.g ${ }^{-1}$ amostra) (SATHE; SALUNKHE, 1981) e winged bean (71,10 g óleo.g $\mathrm{g}^{-1}$ amostra) (SATHE; DESHPANDE; SALUNKHE, 1982).

\subsection{Determinação da estabilidade da emulsão (EE) e da atividade emulsificante (AE) das farinhas de tremoço doce e feijão guandu}

Na Tabela 3 estão apresentados os resultados dos ensaios da estabilidade e atividade das emulsões preparadas a partir das farinhas de tremoço doce e feijão guandu.

A estabilidade das emulsões foi determinada através dos valores de água liberada pela emulsão após centrifugação, sendo que 1,12 g de proteína de tremoço doce liberou $14,35 \mathrm{~mL}$ de água, e a mesma quantidade de proteína de feijão guandu liberou 12,30 mL de água, demonstrando maior estabilidade para essa última emulsão. Porém a quantidade de farinha de feijão guandu requerida para corresponder a $1,12 \mathrm{~g}$ de proteína é maior que a quantidade de farinha de tremoço doce, uma vez que essa última possui maior quantidade de proteína. Já para a atividade de emulsão, representada pela água liberada após o tratamento térmico, observa-se que a farinha de tremoço doce liberou 9,55 $\mathrm{mL}$ de água e a farinha de feijão guandu liberou $2,95 \mathrm{~mL}$. Esses resultados demonstram que o aquecimento proporcionou uma estabilidade maior para a farinha de feijão guandu, indicando maior potencial para essa farinha.

Tabela 3. Propriedades funcionais da farinha de tremoço doce (FTD) e da farinha de feijão guandu (FFG).

\begin{tabular}{lcc}
\hline Propriedades avaliadas & FTD & FFG \\
\hline Absorção de água $^{\mathrm{a}}$ & $3,5-3,6$ & $2,0-2,1$ \\
Absorção de óleo $^{\mathrm{a}}$ & $1,2-1,3$ & $1,0-1,1$ \\
Capacidade de emulsificação $^{\mathrm{b}}$ & 133,07 & 155,21 \\
Atividade da emulsão $^{\mathrm{c}}$ & 9,55 & 2,95 \\
Estabilidade da emulsão $^{\mathrm{c}}$ & 14,35 & 12,30 \\
\hline
\end{tabular}

${ }^{a} \mathrm{~mL} \cdot \mathrm{g}^{-1}$ de farinha.

${ }^{\mathrm{b}} \mathrm{g}$ de óleo.g ${ }^{-1}$ de proteína.

${ }^{\mathrm{c}} \mathrm{mL}$ de água liberada da emulsão.
Os resultados de propriedade de emulsão e suas atividades e estabilidade sinalizam a possibilidade de utilização destes em formulações que utilizam carne, como salsichas, linguiça e fiambres.

\subsection{Determinação das perdas de peso por cocção dos fiambres}

A determinação da perda de peso após cocção também é um parâmetro importante na aplicação tecnológica de um ingrediente alimentício em emulsões, podendo comprometer toda a textura e a aparência do produto final.

Na Tabela 4 estão apresentados os valores de perda de peso para os fiambres após cocção. A partir dos resultados da Tabela 4, observa-se que a farinha de feijão guandu foi a que apresentou menor perda de peso em relação às outras farinhas em estudo, corroborando com os resultados de emulsão apresentados na Tabela 3.

De acordo com Naczk, Rubin e Shahidi (1986), a propriedade de absorção de água de uma proteína determina seu grau de interação com a água. Sathe, Deshpande e Salunkhe (1982) e Sosulski e MCcurdy (1987) sugeriram que a composição das frações proteicas e a sequência de aminoácidos polares e apolares são determinantes na resposta ao teste de capacidade de absorção de água e óleo, uma propriedade funcional de interesse para a elaboração de embutidos cárneos. Nesse caso, o fiambre que perdeu menos água não foi o que absorveu mais água e sim o que teve a melhor atividade e estabilidade de emulsão.

\subsection{Composição química dos \\ fiambres antes e após a cocção}

Os fiambres tiveram sua composição química determinada antes e após o processo térmico a fim de verificar o efeito do processamento nos componentes dos fiambres. Os resultados estão apresentados na Tabela 5.

A partir dos dados apresentados na tabela, verifica-se que os valores de umidade apresentaram diferenças significativas após a cocção, porém, dentro do limite preconizado no regulamento técnico de identidade e qualidade de fiambre; valor máximo de 70\% (BRASIL, 2000). Os valores médios para cinzas e gorduras não apresentaram diferenças significativas. Já as médias de quantidade de proteínas estão acima do limite mínimo (12\%) estabelecido no regulamento técnico de identidade desses produtos. Esse dado aponta o enriquecimento proteico dos fiambres pela adição do

Tabela 4. Avaliação da tagem de perda de peso dos fiambres após cocção.

\begin{tabular}{lc}
\hline \multicolumn{1}{c}{ Fiambres com: } & Perda de peso após cocção (\%) \\
\hline Concentrado proteico de soja & 13,03 \\
Farinha de tremoço doce & 14,44 \\
Farinha de feijão guandu & 6,52 \\
\hline
\end{tabular}


Tabela 5. Composição química dos fiambres com: concentrado proteico de soja (CPS), farinha de tremoço doce (FTD) e farinha de feijão guandu (FFG) anterior e posterior à cocção.

\begin{tabular}{|c|c|c|c|c|c|c|}
\hline \multirow[t]{2}{*}{ Componentes } & \multicolumn{3}{|c|}{ Anterior à cocção* } & \multicolumn{3}{|c|}{ Posterior à cocção* } \\
\hline & CPS & FTD & FFG & CPS & FTD & FFG \\
\hline Umidade $^{\dagger}$ & $69,52^{a} \pm 0,52$ & $70,05^{\mathrm{a}} \pm 0,05$ & $69,97^{a} \pm 0,97$ & $67,39^{\mathrm{b}} \pm 0,39$ & $67,33^{b} \pm 0,33$ & $68,56^{\mathrm{a}, \mathrm{b}} \pm 0,56$ \\
\hline Cinzas $^{\dagger}$ & $3,55^{\mathrm{a}} \pm 0,55$ & $3,37^{\mathrm{a}} \pm 0,37$ & $3,45^{\mathrm{a}} \pm 0,45$ & $3,43^{a} \pm 0,43$ & $3,30^{\mathrm{a}} \pm 0,30$ & $3,39^{\mathrm{a}} \pm 0,39$ \\
\hline Proteína $^{\dagger}$ & $19,88^{\mathrm{b}} \pm 0,88$ & $19,81^{\mathrm{b}} \pm 0,81$ & $19,85^{\mathrm{b}} \pm 0,85$ & $21,48^{\mathrm{a}, \mathrm{b}} \pm 0,48$ & $22,11^{\mathrm{a}} \pm 0,11$ & $21,13^{\mathrm{a}, \mathrm{b}} \pm 0,13$ \\
\hline Calorias $^{\dagger \dagger}$ & $151,84^{c, d} \pm 0,84$ & $150,03^{d} \pm 0,03$ & $152,94^{c} \pm 0,94$ & $174,93^{\mathrm{b}} \pm 0,93$ & $180,74^{\mathrm{a}} \pm 0,74$ & $176,17^{\mathrm{b}} \pm 0,17$ \\
\hline
\end{tabular}

*Os resultados (média \pm desvio padrão de três determinações) seguidos de mesma letra (linha) não diferem no nível de $5 \%$ (p > 0,05), avaliação através do teste de Tukey (AYRES et al., 2005); ${ }^{\dagger} \mathrm{g} .100 \mathrm{~g} ;{ }^{\dagger} \mathrm{Kcal} .100 \mathrm{~g}$.

Tabela 6. Avaliação da textura dos fiambres utilizando a força de cisalhamento $\left(\mathrm{kgf} . \mathrm{cm}^{-2}\right)$.

\begin{tabular}{lc}
\hline \multicolumn{1}{c}{ Fiambres com: } & Kgf.cm $^{-2}$ \\
\hline Concentrado proteico de soja & $0,422 \pm 0,04^{\mathrm{a}}$ \\
Farinha de tremoço doce & $0,404 \pm 0,04^{\mathrm{a}}$ \\
Farinha de feijão guandu & $0,431 \pm 0,07^{\mathrm{a}}$ \\
\hline
\end{tabular}

* Os resultados (média \pm desvio padrão de três determinações) seguidos de mesma letra (coluna) não diferem no nível de $5 \%(\mathrm{p}>0,05)$, avaliação através do teste de Tukey (AYRES et al., 2005).

Tabela 7. Avaliação da cor dos fiambres, utilizando o colorímetro de tristímulus Hunter $\mathrm{L}^{\star}, \mathrm{a}^{*} \mathrm{e} \mathrm{b}^{*}$.

\begin{tabular}{|c|c|c|c|}
\hline \multirow[t]{2}{*}{ Fiambres com: } & \multicolumn{3}{|c|}{ Tratamentos } \\
\hline & $\mathbf{L}^{*}$ & $\mathbf{a}^{*}$ & $\mathbf{b}^{*}$ \\
\hline Concentrado proteico de soja & $68,71 \pm 0,10^{\mathrm{a}}$ & $11,49 \pm 0,16^{\mathrm{b}}$ & $8,17 \pm 0,29^{\mathrm{a}}$ \\
\hline Farinha de tremoço doce & $67,85 \pm 0,47^{\mathrm{b}}$ & $11,87 \pm 0,18^{\mathrm{a}}$ & $7,24 \pm 0,31^{\mathrm{b}}$ \\
\hline Farinha de feijão guandu & $68,57 \pm 0,14^{\mathrm{a}, \mathrm{b}}$ & $11,08 \pm 0,10^{c}$ & $6,86 \pm 0,29^{\mathrm{b}}$ \\
\hline
\end{tabular}

concentrado proteico de soja, farinha de tremoço doce e da farinha de feijão guandu. Um pequeno aumento no teor de proteína após a cocção foi observado, possivelmente devido à perda de umidade.

\subsection{Avaliação da textura dos fiambres cozidos}

Na Tabela 6, apresentam-se os resultados obtidos para a avaliação da textura, indicada nesse caso pela força de cisalhamento necessária para romper os embutidos cozidos.

Apesar de não haver diferenças significativas entre os resultados, observa-se a tendência de melhores texturas para os fiambres obtidos a partir da farinha de feijão guandu, seguidos dos fiambres obtidos a partir do concentrado proteico de soja e da farinha de tremoço doce.

Estes resultados apresentaram semelhanças à observada para os experimentos, nos quais se pretendia determinar a estabilidade e atividade das emulsões.

\subsection{Avaliação da cor dos fiambres}

Considerando-se o impacto que o atributo cor contribui para a avaliação e aquisição de produtos alimentícios pelo consumidor, relevou-se neste estudo a importância de se avaliar esta característica sensorial a fim de se obterem as informações necessárias para verificar se a adição de farinhas de feijão guandu e de tremoço doce seria capaz de promover alterações significativas nos principais parâmetros de cor.

Os resultados da Tabela 7 apontam diferenças estatísticas para a luminosidade $\left(\mathbf{L}^{\star}\right)$, revelando que o fiambre produzido com farinha de tremoço doce apresentou diferença significativa em relação ao fiambre acrescido de soja. Também se observa diferença significativa entre a relação vermelho versus verde $\left(\mathbf{a}^{\star}\right)$, demonstrando maior intensidade para o fiambre produzido a partir da farinha de tremoço doce. Por fim, a relação de amarelo versus azul $\left(\mathbf{b}^{*}\right)$ aponta resultados semelhantes para as farinhas em estudo, entretanto a maior intensidade foi observada para o fiambre produzido a partir da soja.

\subsection{Avaliação das características sensoriais utilizando o teste de aceitação}

O produto final foi avaliado sensorialmente a fim de se verificar sua aceitação em relação à aparência, cor, aroma, sabor, textura e impressão global, e os resultados estão apresentados na Tabela 8 .

A análise de variância realizada a partir dos dados obtidos nos testes de aceitação indicou diferença significativa no parâmetro sabor para o fiambre produzido com a farinha de feijão guandu. Os demais parâmetros avaliados não apresentaram diferenças significativas entre si, porém os resultados obtidos apontam para a indiferença com leve tendência ao gostei ligeiramente. Segundo Teixeira, Meinert e Barbetta (1987), para que um determinado produto seja considerado aceito em termos de suas propriedades sensoriais, deve alcançar índice de aceitação (IA) de no mínimo 70\% (média igual ou superior a 6,3), entretanto a aceitação também depende de outros fatores como preço, qualidade nutricional, disponibilidade e marketing. 
Tabela 8. Avaliação dos atributos sensoriais para aceitação dos provadores dos fiambres elaborados.

\begin{tabular}{|c|c|c|c|c|c|c|}
\hline \multirow[t]{2}{*}{ Fiambres com: } & \multicolumn{6}{|c|}{ Parâmetros } \\
\hline & Aparência & Coloração & Aroma & Sabor & Textura & Impressão global \\
\hline Concentrado proteico de soja & $5,09^{\mathrm{a}}$ & $5,89^{a}$ & $6,00^{\mathrm{a}}$ & $5,91^{\mathrm{a}}$ & $4,72^{\mathrm{a}}$ & $5,48^{\mathrm{a}}$ \\
\hline Farinha de tremoço doce & $4,93^{\mathrm{a}}$ & $5,58^{\mathrm{a}}$ & $4,93^{\mathrm{a}}$ & $5,38^{\mathrm{a}, \mathrm{b}}$ & $4,80^{\mathrm{a}}$ & $5,18^{\mathrm{a}}$ \\
\hline Farinha de feijão guandu & $5,64^{\mathrm{a}}$ & $5,77^{\mathrm{a}}$ & $5,03^{\mathrm{a}}$ & $4,45^{\mathrm{b}}$ & $4,76^{\mathrm{a}}$ & $5,07^{\mathrm{a}}$ \\
\hline
\end{tabular}

* Os resultados (média) seguidos de mesma letra (coluna) não diferem no nível de $5 \%$ (p > 0,05), avaliação através do teste de Tukey (AYRES et al., 2005).

\section{Conclusões}

As farinhas de tremoço doce e de feijão guandu apresentaram boas propriedades de absorção de água e óleo, as farinhas também apresentaram boas propriedades para formar emulsão, assim como sua atividade e estabilidade, indicando viabilidade de utilização como ingrediente alimentício na produção de produtos que utilizam a emulsão para sua elaboração.

A partir da aplicação das farinhas na formulação do produto, pode-se obter fiambres enriquecidos nutricionalmente de acordo com o regulamento técnico para fiambres, mantendo um produto de boa textura. O tratamento estatístico indicou que não houve diferenças significativas nos atributos sensoriais em relação aos fiambres elaborados a partir do concentrado proteico de soja e da farinha de tremoço doce.

Os fiambres elaborados a partir de farinhas de tremoço doce, farinha de feijão guandu e concentrado proteico de soja não tiveram IA satisfatório, o que indica a necessidade de estudos futuros para melhorar os parâmetros sensoriais e a aceitação do produto.

\section{Agradecimentos}

À CAPES, ao PIBIC-CNPq e à Fundação SIBAN pelo apoio financeiro; ao farmacêutico Gerson Kazuyuki Sasaoka e ao técnico de laboratório Osmar Redondo pelo apoio técnico; ao Prof. Dr. Fernando L. FERTONANI e à bibliotecária Sra. Maria IRANI pela revisão de texto; a IRMOR-Distribuidor de Peças para Balanças Ltda. e à indústria de alimentos PREDILECTA S. A. pelo incentivo; à EMBRAPA (Passo Fundo - RS) e ao IAC (Campinas - SP) pelo fornecimento de material.

\section{Referências bibliográficas}

ABBEY, B. W.; IBEH, G. O. Functional properties of raw and heat processed couwpea (Viagna unguiculata) flour. Journal Food Science, v. 53, n. 6, p. 1775-1791, 1988.

ASSOCIAÇÃO BRASILEIRA DE NORMAS TÉCNICAS - ABNT. NBR 13922. Aguardente de cana: determinação de açúcares. São Paulo, 1997.

ACTION, J. C.; SAFFLE, R. L. Stability of oil water emulsions. I Effect of surface tension, level of oil, viscosity and type protein. Journal Food Science, n. 35, p. 852-855, 1970.

ADAWY, T. A. E. et al. Nutritional potential and functional properties of sweet and bitter lupin seed protein isolates. Food Chemistry, v. 74, n. 4, p. 455-462, 2001.

ASSOCIATION OF OFFICIAL ANALYTICAL CHEMISTS - AOAC. Official methods of analysis. $16 \mathrm{ed}$. Washington, 1995.
AYRES, M. et al. BioEstat 4.0: aplicações estatísticas nas áreas das ciências biológicas e médicas. Belém: Sociedade Civil Mamirauá, 2005.

BARBUT, S. Protein ultrastructure and functionality. In: HETTIARACHCHY, N.; ZIEGLER, G. (eds). Protein functionality in food systems. New York: Marcel Dekker, 1994. p. 383-433.

BATISTUTI, J. P.; FREITAS, S. D. Emulsifying properties of flour and protein concentrate of pigeon pea (Cajanus flavus DC.) var. fava larga. Alimentos e Nutrição, v. 6, n. 1, p. 55-67, 1995.

BIBBLE, B. B.; SINGHA, S. Caopy position influences CIELAB coordinates of peach color. Hort Science, v. 28, n. 10, p. 992-993, 1993.

BOBBIO, P. A.; BOBBIO, F. O. Química de processamento de alimentos. São Paulo: Varela, 2001. 142 p.

BRASIL. Ministério da Agricultura, Pecuária e Abastecimento. Instrução Normativa n. 20, de 31 de julho de 2000. Aprova os regulamentos técnicos de identidade e qualidade de almôndega, de apresuntado, de fiambre, de hamburguer, de kibe, de presunto cozido e de presunto. Diário Oficial da União, Poder Executivo, Brasília, DF, 03 de agosto de 2000, Seção 1, p. 7. Disponível em: <http:// extranet.agricultura.gov.br/sislegis-consulta/consultarLegislacao. do? operacao=visualizar\&id=1681 >. Acesso em: 09 fev. 2004.

CEPEDA, E.; VILLARÁN, M. C.; ARANGUIZ, N. Functional properties of faba bean (Vicia faba) protein flour dried by spray drying and freeze drying. Journal Food Engineering, v. 36, n. 3, p. 303-310, 1998.

CHEFTEL, J. C.; CUQ, J. L.; LORIENT, D. Proteines alimentaires. Paris: Techinique et documentation, $1985.309 \mathrm{p}$.

DRAKOS, A.; DOXASTAKIS, G.; KIOSSEOGLOU, V. Functional effects of lupin proteins in comminuted meat and emulsion gels. Food Chemistry, v. 100, n. 2, p. 650-655, 2007.

EL AAL, M. H. Production of guava seed protein isolates: yield, composition and protein quality. Die Nahrung, v. 36, n. 1, p. 5055, 1992.

EMBRAPA. Tabela de composição química e valores energéticos de alimentos para suínos e aves. 3 ed. Concórdia, 1991. 97 p. (Documento, 19)

FONTANARI, G. G. et al. Thermal study and physico-chemical characterization of some functional properties of guava seeds protein isolate (Psidium guajava). Journal of Thermal Analysis and Calorimetry, v. 83, n. 3, p. 709-713, 2006.

FONTANARI, G. G. et al. Isolado protéico de semente de goiaba (Psidium guajava): caracterização de propriedades funcionais. Ciência e Tecnologia de Alimentos, v. 27, n. 1, p. 73-79, 2007.

FONTANARI, G. G. et al. Differential scanning calorimetry of the protein isolate and the major protein fraction of guava seeds (Psidium guajava). Journal of Thermal Analysis and Calorimetry, v. 93, n. 2, p. 397-402, 2008.

INSTITUTO ADOLFO LUTZ - IAL. Normas Analíticas do Instituto Adolfo Lutz. São Paulo, 1976. p. 19-36. (v. 1) 
LAWAL, O. S. Functionality of African locust bean (Parkia biglobossa) protein isolate: effects of $\mathrm{pH}$, ionic strength and various protein concentrations. Food Chemistry, v. 86, n. 3, p. 345-355, 2004.

LIADAKIS, G. N. et al. Protein isolation from tomato seed meal, extraction optimization. Journal Food Science, v. 60, n. 3, p. 477482, 1995.

LQARI, H. et al. Lupinus angustifolius protein isolates: chemical composition, functional properties and protein characterization. Food Chemistry, v. 76, no. 3, p. 349 - 356, 2002.

MARTÍNEZ-VILLALUENGA, C.; FRÍAS, J.; VALVERDE, C. V. Functional lupin seeds (Lupinus albus L. and Lupinus luteus L.) after extraction of $\alpha$-galactosides. Food Chemistry, n. 98, p. 291299, 2006.

NACZK, M.; RUBIN, L. J.; SHAHIDI, F. Functional properties and phytate content of pea protein preparations. Journal Food Science, v. 51, n. 5 , p. $1245-1246,1986$.

NICANOR, A. B. et al. Functional properties of Guava Seed Glutelins. Journal Agricultural Food Chemistry, v. 53, n. 9, p. 3613-3617, 2005.

ORNELLAS, C. B. D.; JUNQUEIRA, R. G.; SILVESTRE, M. P. C. Efeito da adição de $\mathrm{NaCl}$ sobre as propriedades funcionais do plasma bovino e de seus hidrolisados trípticos. Ciencia eTecnologia de Alimentos, v. 20, n. 3, p. 391-397, 2000.

OSHODI, A. A.; EKPERIGIN, M. M. Functional properties of Pigeon pea (Cajanus cajan) flour. Food Chemistry, v. 34, n. 3, p. 187-191, 1989.

POZANI, S.; DOXASTAKIS, G.; KIOSSEOGLOU, V. Functionality of lupin seed protein isolate in relation to its interfacial behaviour. Food Hydrocolloids, v. 16, n. 3, p. 241-247, 2002.
RHEE, K. C. Functionality of soy proteins. In: HETTIARACHCHY, N.; ZIEGLER, G. (eds). Protein functionality in food systems. New York: Marcel Dekker, 1994. p. 311-324.

ROÇA, R. O.; SERRANO, A. M.; BONASSI, I. A. Utilização de toucinho na elaboração de fiambres com carne de frango. Ciência e Tecnologia de Alimentos, v. 8, n. 1, p. 67-76, 1988.

SALUNKHE, D. K.; CHAVAN, J. K.; KADAM, S. S. Pigeon pea as an important food source. Critical Reviews in Food Science and Nutrition, v. 23, n. 2, p. 103-145, 1986.

SATHE, S. K.; SALUNKHE, D. K. Functional properties of the great Northen bean proteins: emulsion, foaming, viscoity and gelation properties. Journal Food Science, v. 46, n. 1, p. 71-81, 1981.

SATHE, S. K.; DESHPANDE, S. S.; SALUNKHE, D. K. Functional properties of Winged bean (Psophocarpus tetragonolobus (L.) DC) proteins. Journal Food Science, v. 47, p. 503-509, 1982.

SILVA, J. B.; BORA, P. S.; QUEIROGA NETO, V. Caracterização de propriedades funcionais do Isolado protéico de semente de algaroba (Prosopis juliflora (SW) D. C.) modificado por acetilação. Ciência e Tecnologia de Alimentos, v. 17, n. 3, p. 263-269, 1997.

SOSULSKI, F. W; MCCURDY, A. R. Functionality of flours, protein fractions and isolates from Field peãs and Faba beans. Journal Food Science, v. 52, n. 4, p. 1010-1014, 1987.

TEIXEIRA, E.; MEINERT, E. M.; BARBETTA, P. A. Análise sensorial de alimentos. Florianópolis: UFSC, 1987. 180 p.

WANG, J. C.; KINSELLA, J. E. Functional properties of novel proteins: alfalfa leaf proteins. Journal Food Science, v. 41, n. 3, p. 286-292, 1976.

WATT, B.; MERRILL, A. L. Composition of foods: raw, processed, prepared. Washington: Consumer and Food Economics Research Division, 1963. 198 p. (Agriculture Handbook, 8). 